\title{
Giant Cell Tumor of the Capitate Bone
}

\author{
Ahmadreza Afshar ${ }^{1} \quad$ Ali Tabrizi ${ }^{1} \quad$ Ali Aidenlou ${ }^{1} \quad$ Ata Abbasi $^{2}$ \\ ${ }^{1}$ Department of Orthopedics, Urmia University of Medical Sciences, \\ Imam Khomeini Hospital, Urmia, Iran \\ 2Department of Pathology, Urmia University of Medical Sciences, \\ Urmia, Iran \\ J Hand Microsurg 2018;10:158-161
}

\begin{abstract}
Address for correspondence Ahmadreza Afshar, MD, Department of Orthopedics, Urmia University of Medical Sciences, Imam Khomeini Hospital, Modaress Street, Ershad Boulevard, Urmia, 57157 81351, Iran (e-mail: afshar_ah@yahoo.com).
\end{abstract}
Abstract
Keywords
- capitate
- giant cell tumor of bone
- hand tumor
- wrist tumor

This case report describes a 16-year-old female patient with a giant cell tumor in her right capitate bone. The tumor was removed by intralesional curettage. A high-speed burr was used to extend the margins of the curettage, and alcohol irrigation was used for adjuvant therapy. The cavity of the capitate was filled with allogenic bone graft. There was no recurrence after 2 years of follow-up, and the right wrist radiographs demonstrated healing of the lesion.

\section{Introduction}

Giant cell tumor (GCT) accounts for approximately $5 \%$ of all tumors in bones. ${ }^{1}$ The incidence of GCTs in bones of the hand is estimated to be between 2 and $5 \%{ }^{1-6}$ However, its occurrence in the carpal bones is extremely rare. There are limited case reports describing the occurrence and treatment of GCTs in the carpal bones, ${ }^{1-15}$ and a few case reports have described GCT in the capitate..$^{1-5,7,8,11}$ Most surgeons advocate the following principles: (1) adequate and thorough debridement; (2) use of adjuvant intralesional therapy; (3) bone grafting; and (4) close regular long-term follow-up to treat GCT in bones.

The current case report presents a case of a GCT in the capitate bone and its treatment.

\section{Case Report}

A 16-year-old female patient complained of pain in the right wrist for 6 months and demonstrated tenderness over the right capitate bone. An anteroposterior radiograph of her right wrist demonstrated a well-defined lytic lesion without sclerotic borders in the capitate bone ( - Fig. 1). A whole-body bone scan demonstrated increased uptake over the right wrist region. The patient obtained a magnetic resonance image (MRI) from the right wrist region. The T1-weighted MRI images demonstrated a low signal intensity lesion in the capitate ( - Fig. 2 ), and the T2-weighted MRI images demonstrated a high signal intensity lesion in the capitate ( - Fig. $\mathbf{3}$ ). Regarding the imaging, there was no sign of a primary malignant tumor. The differential diagnosis of a solitary benign

received

September 8, 2017

accepted after revision

January 11, 2018

published online

March 20, 2018 lytic lesion included an aneurismal bone cyst, unicameral bone cyst, enchondroma, giant cell reparative granuloma, brown tumor of hyperparathyroidism, posttraumatic cyst, or an intraosseous ganglion. The routine preoperative blood laboratory tests for the elective hand surgery were normal.

A direct dorsal approach was used, and the tumor was exposed after longitudinal capsulotomy of the wrist joint ( - Fig. 4). The tumor was laid beneath the joint capsule; however, it was eroded and extended through the dorsal cortex of the capitates. The intracapitate tumor was removed by intralesional curettage. A high-speed burr with rotational speed of $35,000 \mathrm{rpm}$ (revolutions per minute) was used to extend the margins of the curettage, and alcohol irrigation was used for adjuvant therapy. The tumor grossly consisted of multiple pieces of dark-brown tissue with a soft consistency and measured $2 \times 2 \times 2 \mathrm{~cm}$ with a creamy-brown, homogenous cut surface ( $\mathbf{- F i g . 5 )}$ ). The cavity of the capitate was filled with an allogenic bone graft, and the wrist was protected with a short arm cast for 6 weeks.

A histopathologic study of the tumor demonstrated two cellular populations: mononuclear cells and osteoclast-like giant cells. The giant cells were evenly distributed throughout the lesion and contained up to 30 nuclei in each cell. The mononuclear cells were oval shaped with nuclei similar to those in giant cells. Mild mitotic activity was present in mononuclear cells. No evidence of nuclear atypia or atypical mitoses was identified ( - Fig. 6). The histopathologic diagnosis was compatible with GCT of the bone.

The patient's pain resolved after surgery. There was no recurrence or development of lung lesion after 2 years of follow-up,
(C2018 Society of Indian Hand \& Microsurgeons
DOI https://doi.org/ 10.1055/s-0038-1631876. ISSN 0974-3227. 


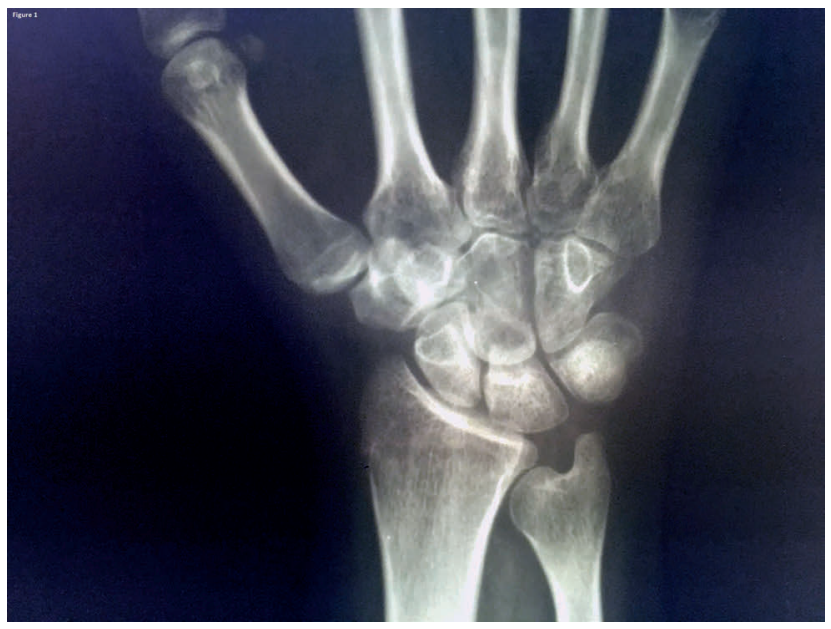

Fig. 1 Anteroposterior wrist radiograph demonstrates a lytic lesion in the right capitates bone.

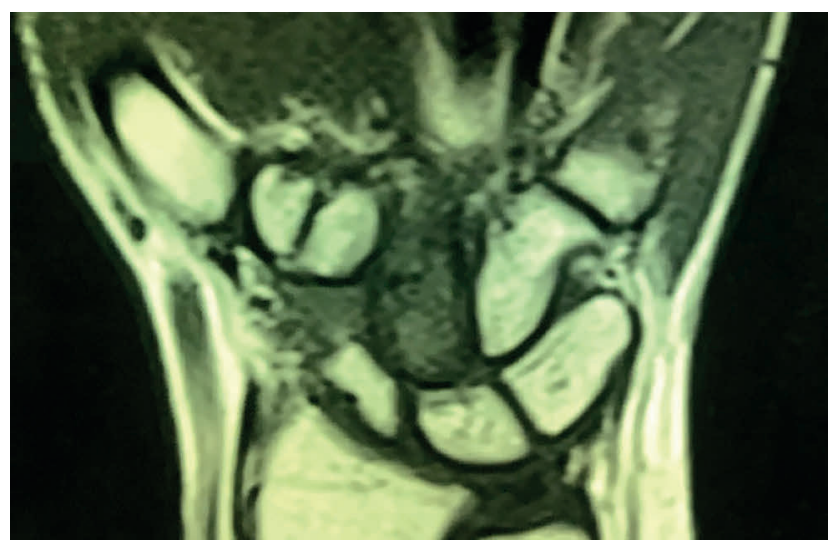

Fig. 2 T1-weighted MRI of the right wrist demonstrates a low signal intensity lesion in the capitate.

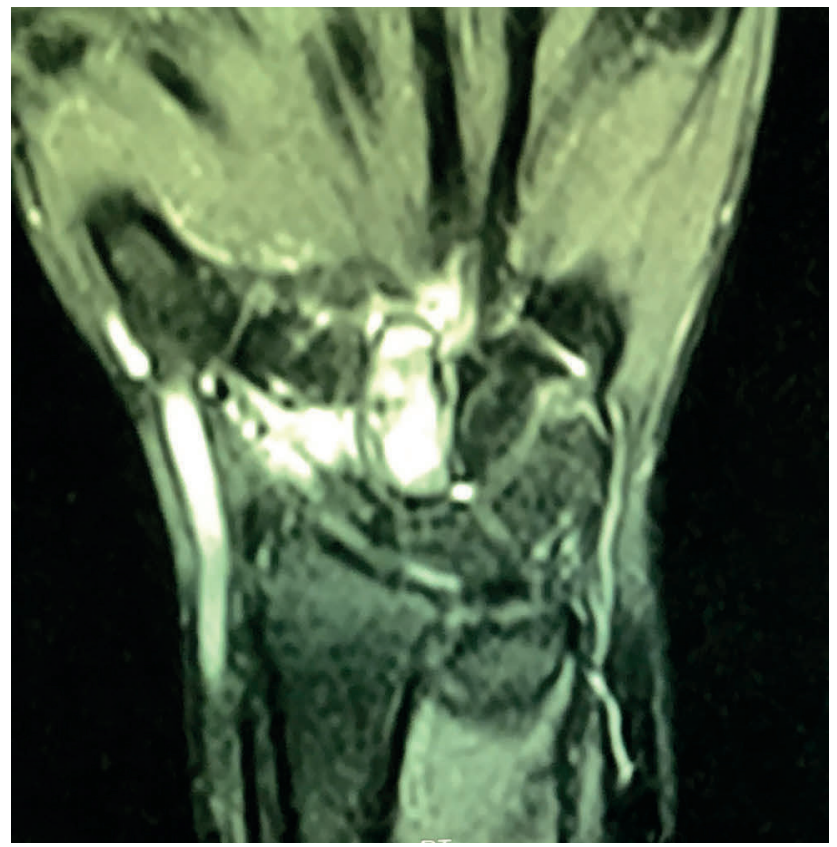

Fig. 3 T2-weighted MRI of the right wrist demonstrates a high signal intensity lesion in the capitate.

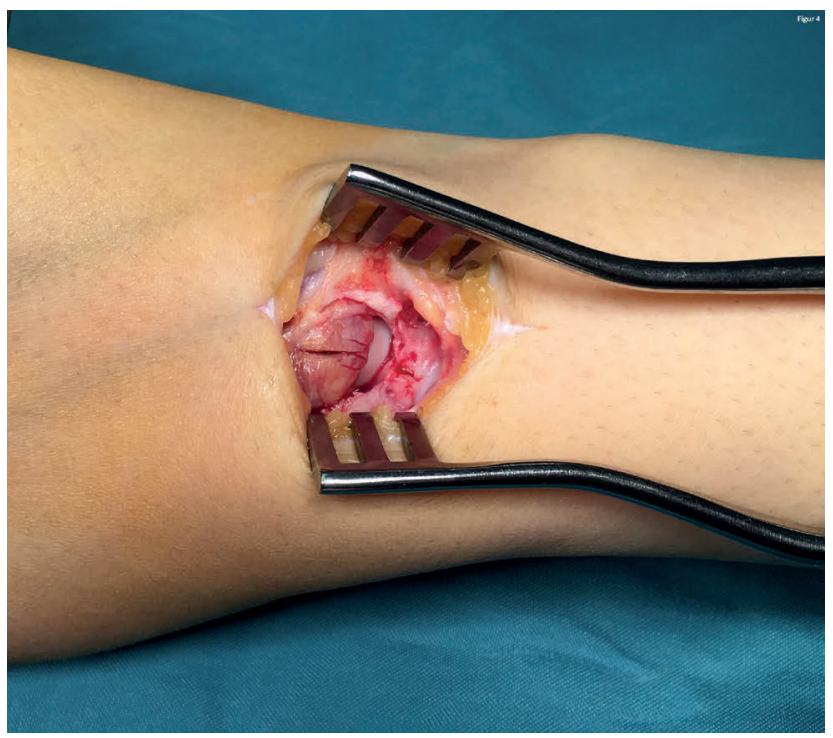

Fig. 4 The tumor is extended through the dorsal cortex of the capitate and exposed after capsulotomy of the wrist joint.

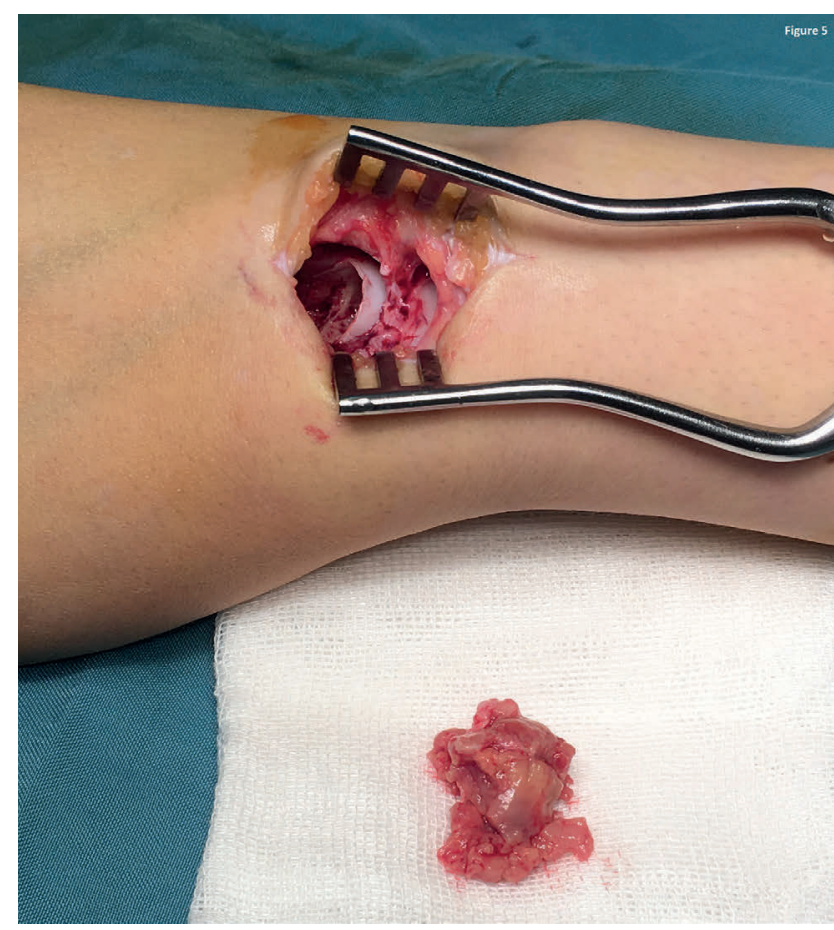

Fig. 5 The tumor consisting of multiple pieces of dark-brown soft tissue with soft consistency measuring $2 \times 2 \times 2 \mathrm{~cm}$ is removed, and the cavity in the capitate is exposed.

and the right wrist radiographs demonstrated healing of the lesion ( - Fig. 7). At 2 years post surgery, the power grip of the right and left hands (Sammons Preston, Warrenville, Illinois, United States) was $35 \mathrm{~kg}$ and $40 \mathrm{~kg}$, respectively. The right wrist flexion/extension range of motion was 160 degrees whereas the left wrist was 170 degrees. The Mayo wrist score was 90 points. ${ }^{16}$ The patient was satisfied with the function of her wrist. The authors intend to follow up with the patient for long term for a probable recurrence or developing of a lung lesion. 


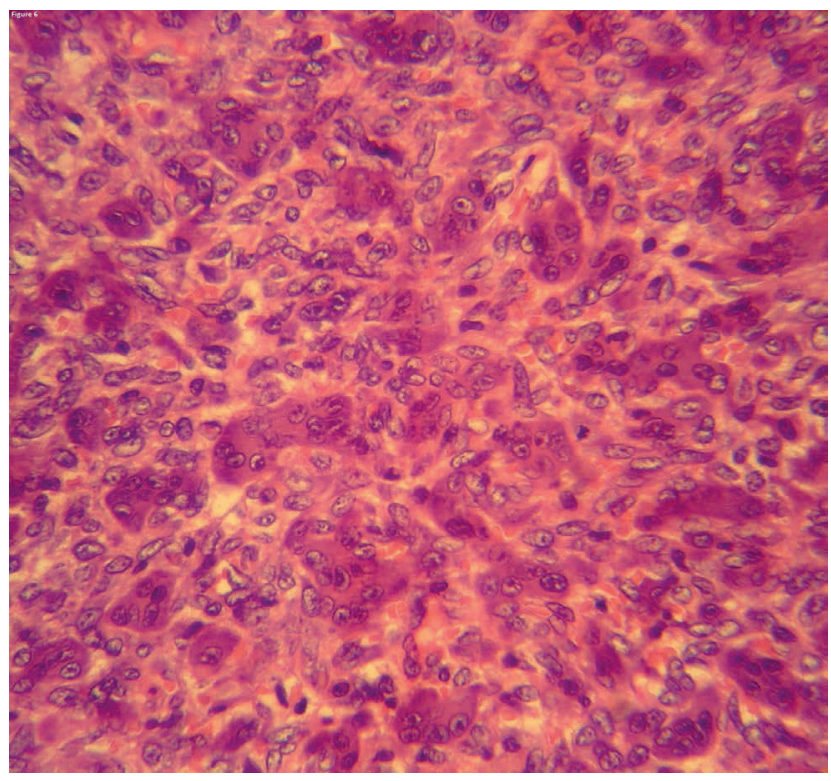

Fig. 6 High-magnification histopathology study demonstrates two cellular populations: mononuclear cells and osteoclast-like giant cells. The giant cells were evenly distributed throughout the lesion. The mononuclear cells were oval shaped with nuclei similar to those in giant cells. A few mitotic activities are present in mononuclear cells. (Hematoxylin and Eosin, $\mathrm{x}$ 400.)

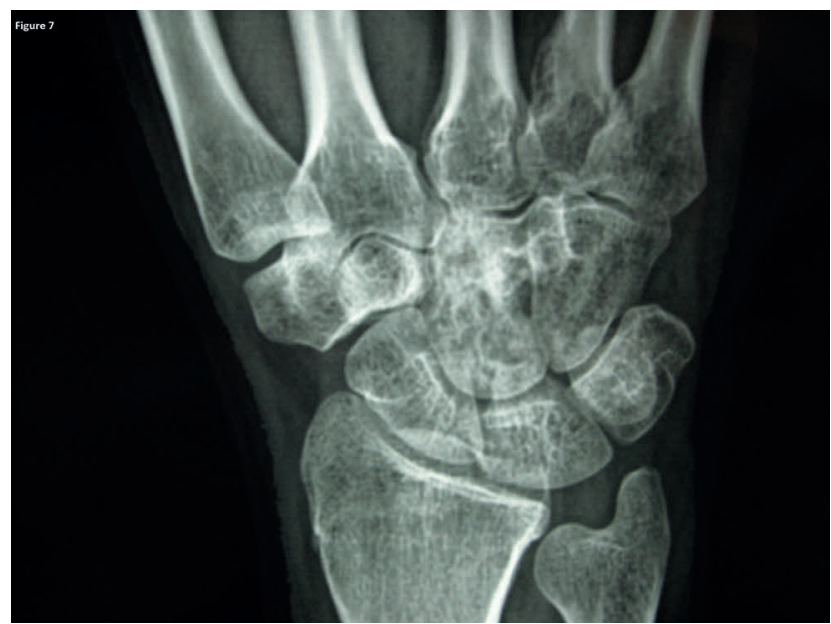

Fig. 7 Anteroposterior radiograph of the right wrist 2 years after surgery demonstrates healing of the lesion.

\section{Discussion}

GCTs are an uncommon tumor of the wrist bones. ${ }^{1-15}$ Averill et al reported 2 GCTs in the hamate and trapezoid bones among 28 GCTs of the hand and wrist bones. ${ }^{12}$ In a review of 1,228 GCTs from 20 articles, there were 4 GCTs in the hamate, lunate, and scaphoid bones. ${ }^{12}$ In a review of 28,600 primary neoplasms of carpal bones between 1909 and 1990, there were two GCTs of the capitate among the five GCTs of the wrist bones. ${ }^{17}$ In another review of 29 reported GCTs of the wrist bones between 1935 and 2005, there were seven GCTs of the capitate. ${ }^{3}$ From 2005 onward, the authors were able to find five reports of GCTs of the capitate bones in the English literature. ${ }^{1,5,7,8,10}$
Although GCTs are generally a benign tumor, they may occasionally demonstrate an aggressive behavior with local recurrence and lung metastasis with a fatal outcome, particularly in the hand and wrist. ${ }^{14,11,12}$ The incidence of recurrence after curettage alone in the hand has been reported to be up to $100 \%, 3,6,7,10,12$ Meanwhile, multifocal GCTs involving several carpal bones has been reported. ${ }^{4,5,12}$ Jackson et al reported a case of recurrent GCT in the head of the fourth metacarpal bone 42 years after curettage and bone graft. ${ }^{18}$ Novais et al reported a case of multicentric GCT of the upper extremities including the left lunate during 16 years of ongoing disease. ${ }^{15}$ It is not clear whether the high incidence of recurrence of the GCT in the hand and wrist bones is due to a real difference in its biological behavior or the difficulties that exist in the complete eradication of the tumor cells from the small bones of the hand and wrist. ${ }^{1,2}$

Because of its rarity, there is no standard surgical treatment for the GCT of the wrist bones. ${ }^{1-14}$ However, complete removal of the tumor is considered to be curative in most cases. Treatment of GCTs of the wrist bones includes intralesional curettage alone, ${ }^{3}$ intralesional curettage with allogenic or autogenous bone grafts, ${ }^{3}$ proximal row carpectomy, ${ }^{14}$ excision of the involved carpal bone, wide resection of the carpal bones, and amputation., ${ }^{3,12}$ The margins of the intralesional curettage can be extended by use of a high-speed burr, cryosurgical ablation, phenol ablation, and polymethyl methacrylate cement application. ${ }^{19}$ Other adjuvant therapies such as hydrogen peroxide and alcohol have also been used. ${ }^{1-15}$ Recurrence rates are higher for curettage alone than for curettage with a bone graft. ${ }^{11,12}$ Recurrence generally requires more aggressive treatment than the initial treatment. ${ }^{12}$ Excision or wide resection of carpal bones may result in wrist instability that needs limited or total carpal arthrodesis. ${ }^{1,12}$ However, McDonald and Schajowicz removed the capitate and did not perform any reconstruction. They reported an excellent functional outcome without recurrence at 5 years follow-up. ${ }^{2}$ Averill et al reported an amputation for a case of GCT with multiple involvements of the carpal bones. ${ }^{12}$ Although radiation therapy may be used for the inoperable GCT in the pelvis or spine, radiation therapy is not recommended in the hand tumors because of its potential complications such as burns, tendon adhesions, and increase in the risk of sarcomatous change. ${ }^{20}$

The patient diagnosed with GCT needs long-term follow-up. Most local recurrence and lung metastasis occur within the first 3 years. Chest radiographs should be obtained at the time of diagnosis to stage the lesion. Computed tomography (CT) of the chest may be obtained as a base line reference. The patients with GCT should obtain radiographs from the primary site and chest at 3 to 4 months interval for 2 years and at 6 months interval for the following year and annually thereafter. Abnormal chest radiograph must be evaluated further with $\mathrm{CT}^{20}$

In the current case, because of its rare occurrence, the diagnosis of a GCT was not considered in our initial differential diagnosis. However, GCTs of the bone should be considered in 
the differential diagnosis of an expansile, well-defined osteolytic lesion with nonsclerotic margins in the carpal bones.

Surgeons may consider treatment of the GCT of the carpal bones to be a challenging problem; however, appropriate treatment is often curative and the patients can achieve satisfactory functional outcomes. In this case, as well as in other reports, meticulous curettage with extended margins, adjuvant therapy with alcohol irrigation and bone grafting was curative and a reasonable wrist functional outcome was achieved. ${ }^{3,8,12}$ Each reported case may hopefully bring more insight to management of the GCTs of the wrist bones.

\section{Conflict of Interest}

None.

\section{References}

1 Angelini A, Mavrogenis AF, Ruggieri P. Giant cell tumor of the capitate. Musculoskelet Surg 2011;95(1):45-48

2 McDonald DJ, Schajowicz F. Giant cell tumor of the capitate. A case report. Clin Orthop Relat Res 1992;(279):264-268

3 Shigematsu K, Kobata Y, Yajima H, Kawamura K, Maegawa N, Takakura Y. Giant-cell tumors of the carpus. J Hand Surg Am 2006;31(7):1214-1219

4 Gupta GG, Lucas GL, Pirela-Cruz M. Multifocal giant cell tumor of the capitate, hamate, and triquetrum: a case report. J Hand Surg Am 1995;20(6):1003-1006

5 Tarng YW, Yang SW, Hsu CJ. Surgical treatment of multifocal giant cell tumor of carpal bones with preservation of wrist function: case report. J Hand Surg Am 2009;34(2):262-265

6 Forthman CL, Segalman KA. Lesions and tumors of the carpus. Hand Clin 2006;22(4):435-446

7 Duman S, Sofu H, Camurcu Y, Gursu S, Oke R. Giant cell tumor of the capitate: an unusual case with 10 years follow-up. SICOT J $2015 ; 1: 18$
8 Narayana Gowda BS, Mohan Kumar J. Giant cell tumor (GCT) of capitate. J Orthop Case Rep 2012;2(1):21-23

9 Wilson SC, Cascio BM, Plauché HR. Giant-cell tumor of the capitate. Orthopedics 2001;24(11):1085-1086

10 Ansari MT, Prakash P K, Machhindra MV. Wrist preserving surgery for multifocal giant cell tumor of carpal bones in a skeletally immature patient: a case report. Orthop Surg 2014;6(4):322-325

11 Howard FM, Lassen K. Giant cell tumor of the capitate. J Hand Surg Am 1984;9(2):272-274

12 Averill RM, Smith RJ, Campbell CJ. Giant-cell tumors of the bones of the hand. J Hand Surg Am 1980;5(1):39-50

13 Abdu WA, Murphy JM, Memoli VA. Giant cell tumor of the scaphoid: a case report and review of the literature. J Hand Surg Am 1994;19(6):1003-1005

14 FitzPatrick DJ, Bullough PG. Giant cell tumor of the lunate bone: a case report. J Hand Surg Am 1977;2(4):269-270

15 Novais EN, Shin AY, Bishop AT, Shives TC. Multicentric giant cell tumor of the upper extremities: 16 years of ongoing disease. J Hand Surg Am 2011;36(10):1610-1613

16 Cooney WP, Bussey R, Dobyns JH, Linscheid RL. Difficult wrist fractures. Perilunate fracture-dislocations of the wrist. Clin Orthop Relat Res 1987;(214):136-147

17 Murray PM, Berger RA, Inwards CY. Primary neoplasms of the carpal bones. J Hand Surg Am 1999;24(5):1008-1013

18 Jackson K, Key C, Fontaine M, Pope R. Recurrence of a giant cell tumor of the hand after 42 years: case report. J Hand Surg Am 2012;37(4):783-786

19 Algawahmed H, Turcotte R, Farrokhyar F, Ghert M. High-speed burring with and without the use of surgical adjuvants in the intralesional management of giant cell tumor of bone: a systematic review and meta-analysis. Sarcoma 2010; 2010:586090

20 Robert K, Heck JR, Toy PC. Benign/aggressive tumors of bone. In: Canale ST, Beaty JH, Campbell WC, eds. Campbell's Operative Orthopaedics. 13th ed. Philadelphia, PA: Elsevier/Mosby; 2017:923-925 